\title{
A Comparison of Post-treatment Quality of Life Outcomes for Endoluminal Brachytherapy and Chemoradiation for the Treatment of Localized Rectal Cancer
}

Azah A Althumairi ${ }^{1}$, Francesca Monn ${ }^{1}$, Joseph M Herman ${ }^{2}$, Amol K Narang ${ }^{2}$, Amy Hacker-Prietz ${ }^{2}$, Jonathan E Efron ${ }^{1}$, Elizabeth C Wick ${ }^{1}$ and Susan L Gearhart $^{1^{*}}$

${ }^{1}$ Department of Surgery, Johns Hopkins University School of Medicine, Baltimore, MD, USA

${ }^{2}$ Department of Radiation Oncology, Johns Hopkins University School of Medicine, Baltimore, MD, USA

*Corresponding author: Susan L Gearhart, M.D., 600 N. Wolfe Street, Blalock 618, Baltimore, MD 21287, USA, Tel: 410-955-7323; Fax: 410-614-9866; E-mail: sdemees1@jhmi.edu

Received date: February 12, 2016; Accepted date: March 26, 2016; Published date: March 31, 2016

Copyright: (C) 2016 Althumairi AA, et al. This is an open-access article distributed under the terms of the Creative Commons Attribution License, which permits unrestricted use, distribution, and reproduction in any medium, provided the original author and source are credited.

\begin{abstract}
Summary: The current study showed that short four day course endoluminal brachytherapy is an effective neoadjuvant treatment for locally advanced rectal cancer; however, it was associated with worsening post-treatment global quality of life and more gastrointestinal symptoms following treatment.
\end{abstract}

Purpose: An attractive alternative to long course neoadjuvant chemoradiation (CRT) for rectal adenocarcinoma is short four day course endoluminal brachytherapy (EBT). However, quality of life (QOL) following EBT is unknown. We aim to compare post-treatment QOL between EBT and CRT.

Methods: 17 patients with localized rectal cancer were prospectively enrolled on a pilot study of EBT. For comparison, prospectively collected QOL for 50 patients received CRT for rectal adenocarcinoma was included. QOL was measured using European Organization for Research and Treatment of Cancer (EORTC QLQ-C30 and EORTC QLQ-CR29) given to patients prior to, during, and at 3-6 weeks following treatment.

Results: Comparing baseline mean scores to $3-6$ weeks following EBT treatment, patients at the end of EBT had lower means scores in global functioning (81.0 vs. 53.0, $p<0.01$ ); role functioning $(90.0$ vs. $63.0, p<0.01$ ); social functioning (91.0 vs. 68.0, $p<0.01)$; increased anxiety (89.0 vs. 62.0, $p<0.01)$; higher scores for pain (11.0 vs. $46.9, p<0.01$ ); fatigue (19.3 vs. $46.2, p<0.01$ ); and buttock pain (17.0 vs. $62.0, p<0.01$ ). Compared to mean difference of scores from baseline to the end of treatment for the control group, patients undergoing EBT had worsening global functioning (28.0 vs. $0, p<0.01)$; physical functioning (12.2 vs. $2.0, p<0.01)$; role functioning (27.1 vs. $3.3, p<0.01)$; social functioning (23.4 vs. $1.0, p<0.01)$; changes in weight $(28.3$ vs. $1.0, p<0.01)$; higher scores for pain (35.8 vs. 6.7, p < 0.01); fatigue (26.9 vs. 1.2, p < 0.01); dysuria (17.9 vs. 5.3, p<0.01); abdominal pain (27.2 vs. $2.8, p<0.01)$; and buttock pain (45.6 vs. $8.0, p<0.01)$.

Conclusion: Although EBT is an effective alternative, rectal cancer patients may experience worse acute preoperative global QOL and more gastrointestinal symptoms following treatment. Efforts should be made to minimize these symptoms during treatment. Further studies are needed to determine the long-term effects of EBT on QOL.

Keywords: Endoluminal brachytherapy (EBT); Neoadjuvant chemoradiation (CRT) Rectal cancer; Quality of life (QOL); EORTC QLQ-C30; EORTC QLQ-CR29

\section{Introduction}

The current standard of care established in large randomized phase III trials for locally advanced distal rectal cancer (stage II and III) is neoadjuvant chemoradiation (CRT) with 5-fluorouracil (5-FU) based chemotherapy and external beam radiation with a total dose of $50.4 \mathrm{~Gy}$ delivered in 28 fractions over 5-6 weeks. Neoadjuvant treatment is then followed with total mesorectal excision (TME) by either a low anterior resection (LAR) or abdominoperineal resection (APR) in $6-8$ weeks [1]. This regimen has been shown to be associated with tumor pathological complete response (pCR) rates of $8.0 \%-19.0 \%$, and local recurrence (LR) rates and overall survival (OS) rates at 10 years of $6.0 \%-11.7 \%$ and $50.7 \%-68.0 \%$, respectively [2-5]. However, this current approach is associated with significant risk of adverse effects on short-term and long-term quality of life (QOL) [6]. In particular, strong associations with poor social and emotional functioning, poor body image and sexuality, defecatory dysfunction, and pain have been demonstrated following treatment for rectal cancer [7-9].

In an attempt to improve QOL by decreasing treatment side effects, long term effects, and shortening the duration of therapy, investigators at McGill University have investigated high dose rate endorectal brachytherapy (EBT) as a neoadjuvant monotherapy for locally advanced rectal cancer [10]. This treatment consists of 4 fractions of 6.5 Gy given over 4 consecutive days followed by surgery (TME) in 4 8 weeks [10]. With this technique, a focused high dose of ionizing 
Citation: Althumairi AA, Monn F, Herman JM, Narang AK, Hacker-Prietz A, et al. (2016) A Comparison of Post-treatment Quality of Life Outcomes for Endoluminal Brachytherapy and Chemoradiation for the Treatment of Localized Rectal Cancer. Arch Surg Oncol 2: 112. doi:10.4172/2471-2671.1000112

Page 2 of 8

radiation is delivered to the tumor only, limiting the dose of radiation to adjacent normal structures including small bowel, bladder, prostate and skin $[10,11]$. In the McGill series of 47 patients, the pathologic CR rate was $32.0 \%$, the 5 year LR rate was $5.0 \%$, and the DFS was $65.0 \%$ [10]. This neoadjuvant monotherapy delivered over short periods of time and resulting in high pCR rates is a very attractive modality but little is known about the treatment related toxicity and its impact on patient related QOL. At our institution, we performed the first prospective trial to examine the changes in symptoms and QOL of rectal cancer patients undergoing EBT for locally advanced disease. Our objectives were to assess post-treatment symptoms and QOL using validated questionnaires given prior to, during and after EBT monotherapy and compare these results to the same QOL questionnaires that were prospectively collected from rectal cancer patients treated with conventional CRT.

\section{Methods}

\section{Study participants (Study group)}

From 2010 to 2014, patients with histologically proven locally advanced rectal adenocarcinoma within $12 \mathrm{~cm}$ from the anal verge were prospectively enrolled in an institutional pilot study of EBT (NCT01226979). This study was approved by the institutional review board and written informed consents were obtained from all participants. Inclusion criteria included age greater than 18 , and staging by magnetic resonance imaging (MRI) and / or endorectal ultrasound (EUS) demonstrating T1-3 N0-2. Patients were excluded if they had metastatic disease at the time of enrollment, concurrent other malignancy, tumors that would not allow endorectal probe insertion, or previous pelvic radiation.

Endoscopic assessment of the rectal tumor was performed with placement of fiducial markers proximal and distal to the tumor. EBT was performed via insertion of a flexible silicone endorectal applicator that delivered a high, non-uniform dose of RT (6.5 Gy per day on four consecutive days) to the rectal tumor and surrounding mesorectum. The applicator was positioned in the rectum using MRI guidance while in lithotomy position and each fraction was delivered over approximately 15 minutes using a micro Selectron high-dose-rate iridium-192 remote after loading system (Nucletron). Treatment planning was performed using the Oncentra brachytherapy planning system (Nucletron) [10]. The type of surgery performed (LAR vs. APR) was determined at the discretion of the surgeon.

Assessment of clinical response rates was performed by comparing direct endoscopic visualization at initial evaluation with inspection prior to resection and by sequential imaging with pelvic MRI and positron emission tomography (PET) / CT scan performed at an average period of one month following the completion of treatment and prior to surgical resection. To determine pathological response, a designated single pathologist examined each surgical specimen. For the designation of $\mathrm{pCR}$, no viable tumor cells could be present within the primary tumor. Following EBT, patients received 5-FU based chemotherapy at the discretion of their oncologist.

\section{Study participants (Control group)}

From 2006 to 2010, 50 patients undergoing neoadjuvant CRT for locally advanced rectal adenocarcinoma (T3, T4 or node positive disease on imaging) were enrolled in a prospective study to examine QOL as previously reported [6]. Similar to the study group, patients were evaluated with laboratory studies and staged with appropriate imaging studies. Radiation therapy was administered at 1.8 Gy to 2.0 Gy doses according to the standard 3-field technique. The whole pelvis was treated with $45 \mathrm{~Gy}$ followed by a 5.4 Gy boost to the primary tumor and involved lymphadenopathy. Concurrent chemotherapy was given in the form of oral capecitabine 7 days a week for a dosage of 825 $\mathrm{mg} / \mathrm{m}^{2}$ twice daily.

\section{General and colorectal QOL assessment}

The validated QOL instruments included in this study are the European Organization for Research and Treatment of Cancer (EORTC) QLQ-C30 and the EORTC QLQ-CR29. The QLQ-C30 is general cancer instrument which consists of 30-items that evaluate global QOL, 5 functional scales, (physical, role, cognitive, emotional, and social), and 9 symptom scales (fatigue, nausea / vomiting, pain, dyspnea, sleep disturbance, appetite loss, constipation, diarrhea, and financial impact) [12]. The EORTC QLQ-CR29 contains 29-items that evaluate 3 functional QOL items (body image, anxiety, weight) and 14 symptom items (urinary frequency, blood and mucus in stool, stool frequency, urinary incontinence, dysuria, abdominal pain, buttock pain, bloated feeling, dry mouth, hair loss, trouble with taste, flatulence, fecal incontinence, sore skin) that are associated with colorectal cancer and its treatment [13]. There are different scales for patients with or without stoma, and different questions to evaluate sexual function for men and women [13].

For both QLQ-C30 and QLQ-CR29, the responses are scored on a Likert scale of 4 response categories. Higher functional and global QOL domain scores indicated increased function and better QOL, and higher symptom scores represent worse symptoms. Both questionnaires were administered to patients undergoing EBT at 3 time points: (1) within 4 weeks before the start of EBT; (2) during the 4 day treatment; and (3) at a 3-6 weeks follow-up visit after the end of EBT. For the control group undergoing conventional neoadjuvant therapy, the validated questionnaires were administered (1) within 3 weeks prior to starting therapy, (2) during the $4^{\text {th }}$ week of chemoradiation therapy, and (3) one month following therapy at a follow-up clinic visit.

\section{Provider-rated toxicity scores}

Patients were interviewed by a healthcare provider to determine the presence of the following treatment-related toxicities: urinary frequency, urinary incontinence, bladder spasms, cystitis, diarrhea, stool incontinence, prostatitis, nausea, vomiting, dehydration, vaginal mucositis, and dermatitis. In accordance with the National Cancer Institute Common Terminology Criteria for Adverse Events, version 4.0 , toxicities were graded $1-5$ at the same intervals that the QOL surveys were administered.

\section{Statistical analysis}

Using EORTC scoring methodology, the responses to the QOL questionnaires were linearly transformed to produce a semicontinuous 0 to 100 score [14]. Missing responses were treated according to EORTC procedures. Means and standard errors were calculated for all scale and single-item scores at each time point. Initial comparisons were made between EBT and CRT for pre-treatment QOL. To understand the effect on QOL of this new monotherapy, changes in all outcome variables between pretreatment, midtreatment, and post-treatment scores were then evaluated for EBT 
Citation: Althumairi AA, Monn F, Herman JM, Narang AK, Hacker-Prietz A, et al. (2016) A Comparison of Post-treatment Quality of Life Outcomes for Endoluminal Brachytherapy and Chemoradiation for the Treatment of Localized Rectal Cancer. Arch Surg Oncol 2: 112. doi:10.4172/2471-2671.1000112

Page 3 of 8

patients only. Finally, these outcome variables were then compared to the control group at each respective time points. Results of the analysis between pre and post treatment outcomes are reported in the text as the absolute mean for all symptoms and QOL scores. Significant differences in scores at all treatment points between the study and control group are shown in graphic form. To correct for multiple comparisons, $\mathrm{p}$ values $<0.01$ were considered statistically significant. Furthermore, only mean differences of $\geq 10$ percentage points were considered clinically significant according to prior convention [15]. All statistical tests were conducted by use of the SAS system, version 9.2 (SAS Institute Inc., Cary, NC).

\section{Results}

18 patients were enrolled in the study group. Completed surveys at all-time points were available on 17 patients included in the analysis. When compared with the control group, patients undergoing EBT did not show a difference in mean age ( 59.0 vs. 54.0 years, $\mathrm{p}=0.826)$ or race $(80.0 \%$ vs. $76.0 \%$, white, $p=0.999)$, respectively. However, more female patients underwent EBT than CRT, (59.0\% vs. $28.0 \%, \mathrm{p}=0.02$, respectively). Grade 3 toxicity occurred in 5 (31.0\%) patients following EBT vs. 8 (16.0\%) patients undergoing conventional CRT, p $=0.276$. In the EBT group, $15(88.0 \%)$ patients underwent sphincter-sparing surgery and the pathological complete response rate was $28.0 \%$.

Baseline pre-treatment QOL differed between patients undergoing EBT vs. CRT. Patients scheduled to undergo EBT had better global functioning scores $(81.1$ vs. $70.33, \mathrm{p}<0.01)$ and less anxiety $(88.9$ vs. 54.67, $\mathrm{p}<0.01)$ than patients scheduled to undergo CRT. However, EBT patients had more concerns over hair loss (41.7 vs. $0.66, \mathrm{p}<0.01)$ and troubles with taste $(33.3$ vs. $4, \mathrm{p}<0.01)$ when compared to CRT, respectively (Tables 1 and 2). Comparing pre-treatment baseline scores to 3 - 6 weeks post-treatment mean scores, patients undergoing EBT had the following: lower global QOL (81.0 vs. 53.0, p $<0.01)$; lower role functioning ( 90.0 vs. $63.0, \mathrm{p}<0.01)$; lower social functioning $(91.0$ vs. $68.0, \mathrm{p}<0.01)$; and increased anxiety $(89.0$ vs. $62.0, \mathrm{p}<0.01)$. Higher symptoms scores were noted for general pain (11.0 vs. $46.9, \mathrm{p}<$ 0.01 ); fatigue ( 19.3 vs. $46.2, \mathrm{p}<0.01)$; and buttock pain ( 17.0 vs. $62.0, \mathrm{p}$ $<0.01)$ as shown in Tables 3 and 4 .

\begin{tabular}{|l|l|l|l|l|l|l|l|l|}
\hline C30 & $\begin{array}{l}\text { EBT Mean Pre- } \\
\text { treatment }\end{array}$ & SE & N & $\begin{array}{l}\text { CRT Mean Pre- } \\
\text { treatment }\end{array}$ & SE & N & Mean difference & p-value \\
\hline Physical functioning & 90.8 & 3.4 & 16 & 88.27 & 2.47 & 50 & 2.53 & 0.299 \\
\hline Role functioning & 89.6 & 4.3 & 16 & 81.33 & 3.83 & 50 & 8.27 & 0.128 \\
\hline Cognitive functioning & 87.8 & 4.4 & 15 & 86 & 2.75 & 50 & 1.8 & 0.373 \\
\hline Emotional functioning & 79.4 & 3.3 & 15 & 74.17 & 2.7 & 50 & 10 & 0.162 \\
\hline Social functioning & 91.1 & 3.6 & 15 & 77.33 & 4.12 & 50 & 13.77 & 0.041 \\
\hline Nausea / vomiting & 3.1 & 1.7 & 16 & 5.15 & 1.73 & 50 & -2.05 & 0.738 \\
\hline Dyspnea & 6.7 & 3.6 & 15 & 7.27 & 15.56 & 49 & -0.57 & 0.508 \\
\hline Pain & 11.1 & 4.2 & 15 & 25 & 4.29 & 50 & -13.9 & 0.952 \\
\hline Fatigue & 19.3 & 3.5 & 15 & 26.22 & 3.5 & 50 & -6.92 & 0.847 \\
\hline Insomnia & 15.6 & 5.5 & 15 & 30.67 & 4.55 & 50 & -15.07 & 0.953 \\
\hline Appetite loss & 10.4 & 5.0 & 16 & 13.3 & 3.16 & 50 & 7.24 & 0.677 \\
\hline Constipation & 15.6 & 7.2 & 15 & 21.33 & 3.9 & 50 & -5.73 & 0.758 \\
\hline Diarrhea & 17.8 & 7.9 & 15 & 20 & 3.69 & 50 & -2.2 \\
\hline Financial Difficulties & 11.1 & 4.2 & 15 & 20.67 & 4.25 & 50 & -9.57 & 0.608 \\
\hline Global functioning & 81.1 & 2.9 & 15 & 70.33 & 3.13 & 50 & 10.77 & 0.871 \\
\hline
\end{tabular}

Table 1: Comparison between EBT and CRT pre-treatment mean QOL scores using EORTC C30.

\begin{tabular}{|l|l|l|l|l|l|l|l|l|}
\hline CR29 & $\begin{array}{l}\text { EBT Mean Pre- } \\
\text { treatment }\end{array}$ & SE & N & $\begin{array}{l}\text { CRT Mean Pre- } \\
\text { treatment }\end{array}$ & SE & N & Mean Difference & p-value \\
\hline Anxiety & 88.9 & 4.2 & 15 & 54.67 & 4.64 & 50 & 34.23 & 0.0001 \\
\hline Weight & 64.4 & 9.5 & 15 & 88.01 & 2.65 & 50 & -23.61 & 0.999 \\
\hline Urinary frequency & 28.1 & 7.9 & 16 & 22.85 & 2.59 & 49 & 5.25 & 0.206 \\
\hline Blood and mucus in stool & 14.4 & 4.6 & 15 & 27.3 & 4.41 & 50 & -12.9 & 0.962 \\
\hline
\end{tabular}


Citation: Althumairi AA, Monn F, Herman JM, Narang AK, Hacker-Prietz A, et al. (2016) A Comparison of Post-treatment Quality of Life Outcomes for Endoluminal Brachytherapy and Chemoradiation for the Treatment of Localized Rectal Cancer. Arch Surg Oncol 2: 112. doi:10.4172/2471-2671.1000112

Page 4 of 8

\begin{tabular}{|c|c|c|c|c|c|c|c|c|}
\hline Stool frequency & 21.1 & 3.4 & 15 & 27.79 & 4.41 & 48 & -6.69 & 0.792 \\
\hline Urinary incontinence & 6.3 & 3.4 & 16 & 6.21 & 1.85 & 49 & 0.09 & 0.491 \\
\hline Dysuria & 2.1 & 2.1 & 16 & 5.33 & 1.74 & 50 & -3.23 & 0.833 \\
\hline Abdominal pain & 6.3 & 3.4 & 16 & 14.13 & 2.9 & 49 & -7.83 & 0.922 \\
\hline Buttock pain & 16.7 & 5.3 & 16 & 36.6 & 5.15 & 50 & -19.9 & 0.987 \\
\hline Bloated feeling & 14.6 & 4.3 & 16 & 21.99 & 3.51 & 50 & -7.39 & 0.863 \\
\hline Dry mouth & 6.7 & 3.6 & 15 & 20.66 & 4.35 & 50 & -13.96 & 0.952 \\
\hline Hair loss & 41.7 & 5.7 & 16 & 0.66 & 0.69 & 48 & 41.04 & $<0.0001$ \\
\hline Trouble with taste & 33.3 & 6.8 & 16 & 4 & 1.82 & 50 & 29.3 & $<0.0001$ \\
\hline Flatulence & 16.7 & 6.1 & 16 & 21.24 & 4.12 & 48 & -4.51 & 0.714 \\
\hline Fecal incontinence & 0 & 0 & 14 & 11.62 & 3.96 & 45 & -11.62 & 0.945 \\
\hline Sore skin & 0 & 0 & 16 & 20.31 & 3.98 & 49 & -20.31 & 0.997 \\
\hline
\end{tabular}

Table 2: Comparison between EBT and CRT pre-treatment mean QOL scores using EORTC C29.

\begin{tabular}{|c|c|c|c|c|c|c|c|c|c|}
\hline C30 & $\begin{array}{l}\text { EBT Mean Pre- } \\
\text { treatment }\end{array}$ & SE & $\mathbf{N}$ & $\begin{array}{l}\text { EBT Mean } 3-6 w \\
\text { Post-treatment }\end{array}$ & SE & $\mathbf{N}$ & Mean difference & SE & p-value \\
\hline Physical functioning & 90.8 & 3.4 & 16 & 78.7 & 4.9 & 15 & 12.2 & 5.9 & 0.0484 \\
\hline Role functioning & 89.6 & 4.3 & 16 & 62.5 & 8.4 & 16 & 27.1 & 9.4 & 0.0074 \\
\hline Cognitive functioning & 87.8 & 4.4 & 15 & 72.9 & 7.0 & 16 & 14.9 & 8.4 & 0.0865 \\
\hline Emotional functioning & 79.4 & 3.3 & 15 & 69.4 & 5.8 & 15 & 10 & 6.7 & 0.1486 \\
\hline Social functioning & 91.1 & 3.6 & 15 & 67.7 & 7.0 & 16 & 23.4 & 8.1 & 0.0071 \\
\hline Nausea / vomiting & 3.1 & 1.7 & 16 & 9.4 & 2.6 & 16 & -6.3 & 3.1 & 0.0538 \\
\hline Dyspnea & 6.7 & 3.6 & 15 & 6.3 & 3.4 & 16 & 0.42 & 4.9 & 0.9327 \\
\hline Pain & 11.1 & 4.2 & 15 & 46.9 & 7.3 & 16 & -35.8 & 8.6 & 0.0003 \\
\hline Fatigue & 19.3 & 3.5 & 15 & 46.2 & 6.4 & 16 & -26.9 & 7.5 & 0.0012 \\
\hline Insomnia & 15.6 & 5.5 & 15 & 39.6 & 10.6 & 16 & -24.0 & 12.2 & 0.0589 \\
\hline Appetite loss & 10.4 & 5.0 & 16 & 25.0 & 6.5 & 16 & -14.6 & 8.2 & 0.0846 \\
\hline Constipation & 15.6 & 7.2 & 15 & 45.8 & 9.6 & 16 & -30.3 & 12.1 & 0.0180 \\
\hline Diarrhea & 17.8 & 7.9 & 15 & 22.9 & 6.6 & 16 & -5.1 & 10.2 & 0.6194 \\
\hline Financial Difficulties & 11.1 & 4.2 & 15 & 24.4 & 10.5 & 15 & -13.3 & 11.3 & 0.2492 \\
\hline Global functioning & 81.1 & 2.9 & 15 & 53.1 & 5.4 & 16 & 28.0 & 6.3 & 0.0001 \\
\hline
\end{tabular}

Table 3: Comparison between EBT mean pre-treatment and 3-6 weeks post-treatment score using EORTC C30.

\begin{tabular}{|l|l|l|l|l|l|l|l|l|l|l|l|}
\hline C30 & $\begin{array}{l}\text { EBT Mean Pre- } \\
\text { treatment }\end{array}$ & SE & N & $\begin{array}{l}\text { EBT Mean 3-6w } \\
\text { Post-treatment }\end{array}$ & SE & N & Mean difference & SE \\
\hline Physical functioning & 90.8 & 3.4 & 16 & 78.7 & 4.9 & 15 & 12.2 \\
\hline Role functioning & 89.6 & 4.3 & 16 & 62.5 & 8.4 & 16 & 27.1 & 0.0484 \\
\hline Cognitive functioning & 87.8 & 4.4 & 15 & 72.9 & 7.0 & 16 & 14.9 \\
\hline
\end{tabular}


Citation: Althumairi AA, Monn F, Herman JM, Narang AK, Hacker-Prietz A, et al. (2016) A Comparison of Post-treatment Quality of Life Outcomes for Endoluminal Brachytherapy and Chemoradiation for the Treatment of Localized Rectal Cancer. Arch Surg Oncol 2: 112. doi:10.4172/2471-2671.1000112

Page 5 of 8

\begin{tabular}{|c|c|c|c|c|c|c|c|c|c|}
\hline Emotional functioning & 79.4 & 3.3 & 15 & 69.4 & 5.8 & 15 & 10 & 6.7 & 0.1486 \\
\hline Social functioning & 91.1 & 3.6 & 15 & 67.7 & 7.0 & 16 & 23.4 & 8.1 & 0.0071 \\
\hline Nausea / vomiting & 3.1 & 1.7 & 16 & 9.4 & 2.6 & 16 & -6.3 & 3.1 & 0.0538 \\
\hline Dyspnea & 6.7 & 3.6 & 15 & 6.3 & 3.4 & 16 & 0.42 & 4.9 & 0.9327 \\
\hline Pain & 11.1 & 4.2 & 15 & 46.9 & 7.3 & 16 & -35.8 & 8.6 & 0.0003 \\
\hline Fatigue & 19.3 & 3.5 & 15 & 46.2 & 6.4 & 16 & -26.9 & 7.5 & 0.0012 \\
\hline Insomnia & 15.6 & 5.5 & 15 & 39.6 & 10.6 & 16 & -24.0 & 12.2 & 0.0589 \\
\hline Appetite loss & 10.4 & 5.0 & 16 & 25.0 & 6.5 & 16 & -14.6 & 8.2 & 0.0846 \\
\hline Constipation & 15.6 & 7.2 & 15 & 45.8 & 9.6 & 16 & -30.3 & 12.1 & 0.0180 \\
\hline Diarrhea & 17.8 & 7.9 & 15 & 22.9 & 6.6 & 16 & -5.1 & 10.2 & 0.6194 \\
\hline Financial Difficulties & 11.1 & 4.2 & 15 & 24.4 & 10.5 & 15 & -13.3 & 11.3 & 0.2492 \\
\hline Global functioning & 81.1 & 2.9 & 15 & 53.1 & 5.4 & 16 & 28.0 & 6.3 & 0.0001 \\
\hline
\end{tabular}

Table 4: Comparison between EBT mean pre-treatment and 3-6 weeks post-treatment score using EORTC CR29.

When comparing to mean difference of scores from baseline to $3-6$ weeks following treatment, body image and functional outcomes for patients undergoing EBT were worse for the following items as compared to conventional CRT: global functioning (28.0 vs. $0, \mathrm{p}<$ $0.01)$; physical functioning (12.2 vs. $2.0, \mathrm{p}<0.01)$; role functioning (27.1 vs. $3.3, \mathrm{p}<0.01$ ); social functioning (23.4 vs. $1.0, \mathrm{p}<0.01$ ); and changes in weight $(28.3$ vs. $1.0, \mathrm{p}<0.01)$. Worsening mean differences in symptoms scores for patients undergoing EBT as compared to conventional CRT were seen in general pain (35.8 vs. $6.7, \mathrm{p}<0.01)$; fatigue (26.9 vs. $1.2, \mathrm{p}<0.01)$; dysuria (17.9 vs. $5.3, \mathrm{p}<0.01)$; abdominal pain $(27.2$ vs. $2.8, \mathrm{p}<0.01)$; and buttock pain ( 45.6 vs. $8.0, \mathrm{p}$ $<0.01$ ), respectively, as shown in Tables 5 and 6 . Raw mean scores for the comparison at all-time points are shown for the scores on the EORTC C30 in Figure 1. Raw mean scores for the comparison at alltime points are shown for the scores on the EORTC QLQ-CR29 in Figure 2. Improved QOL for EBT patients as compared to conventional CRT patients was seen in the symptoms scores of nausea and vomiting and in trouble with taste.

\begin{tabular}{|c|c|c|c|c|c|c|c|}
\hline C30 & $\begin{array}{l}\text { EBT } \\
\text { Difference }\end{array}$ & EBT SE & $\mathbf{N}$ & $\begin{array}{l}\text { CRT } \\
\text { Difference }\end{array}$ & CRT SE & $\mathbf{N}$ & p-value \\
\hline Physical functioning & 12.2 & 5.9 & 15 & -2 & 1.91 & 50 & 0.0038 \\
\hline Role functioning & 27.1 & 9.4 & 16 & 3.33 & 3.37 & 50 & 0.0040 \\
\hline Cognitive functioning & 14.9 & 8.4 & 15 & 3 & 2.32 & 50 & 0.0597 \\
\hline Emotional functioning & 10 & 6.7 & 15 & 4.67 & 2.83 & 50 & 0.4023 \\
\hline Social functioning & 23.4 & 8.1 & 15 & -0.67 & 3.23 & 50 & 0.0017 \\
\hline Nausea / vomiting & -6.3 & 3.1 & 16 & 3.27 & 1.66 & 49 & 0.0065 \\
\hline Dyspnea & 0.42 & 4.9 & 15 & 1.39 & 2.52 & 49 & 0.8553 \\
\hline Pain & -35.8 & 8.6 & 15 & -6.67 & 4.31 & 50 & 0.0023 \\
\hline Fatigue & -26.9 & 7.5 & 15 & -1.22 & 2.92 & 50 & 0.0003 \\
\hline Insomnia & -24.0 & 12.2 & 15 & -7.33 & 4.69 & 50 & 0.1285 \\
\hline Appetite loss & -14.6 & 8.2 & 16 & -2 & 3.62 & 50 & 0.1150 \\
\hline Constipation & -30.3 & 12.1 & 15 & -7.33 & 4.07 & 50 & 0.0237 \\
\hline Diarrhea & -5.1 & 10.2 & 15 & -8 & 4.32 & 50 & 0.7646 \\
\hline Financial Difficulties & -13.3 & 11.3 & 15 & 9.33 & 3.16 & 50 & 0.0090 \\
\hline
\end{tabular}


Citation: Althumairi AA, Monn F, Herman JM, Narang AK, Hacker-Prietz A, et al. (2016) A Comparison of Post-treatment Quality of Life Outcomes for Endoluminal Brachytherapy and Chemoradiation for the Treatment of Localized Rectal Cancer. Arch Surg Oncol 2: 112. doi:10.4172/2471-2671.1000112

Page 6 of 8

\begin{tabular}{|l|l|l|l|l|l|l|l|}
\hline Global functioning & 28.0 & 6.3 & 15 & 0.33 & 3.32 & 50 & 0.0002 \\
\hline
\end{tabular}

Table 5: Comparison between EBT and CRT mean score difference between pre-treatment and 3-6 weeks post-treatment score using EORTC C30.

\begin{tabular}{|c|c|c|c|c|c|c|c|}
\hline CR29 & EBT Mean Difference & EBT SE & $\mathbf{N}$ & $\begin{array}{ll}\text { CRT } & \text { Mean } \\
\text { Difference } & \end{array}$ & CRT SE & $\mathbf{N}$ & p-value \\
\hline Anxiety & 27.4 & 9.6 & 13 & 4.67 & 4.47 & 50 & 0.023 \\
\hline Weight & 28.3 & 13.1 & 12 & 0.67 & 3.6 & 50 & 0.004 \\
\hline Urinary frequency & -6.9 & 10.8 & 15 & 3.48 & 3.31 & 49 & 0.2213 \\
\hline Blood and mucus in stool & -15.0 & 7.0 & 13 & -16.38 & 3.85 & 47 & 0.8664 \\
\hline Stool frequency & -17.8 & 6.7 & 15 & -14.49 & 4.67 & 44 & 0.7141 \\
\hline Urinary incontinence & -4.9 & 7.6 & 15 & 1.12 & 2.91 & 49 & 0.2873 \\
\hline Dysuria & -17.9 & 6.5 & 15 & 5.33 & 2.9 & 50 & 0.0005 \\
\hline Abdominal pain & -27.1 & 10.5 & 15 & -2.8 & 2.53 & 48 & 0.0016 \\
\hline Buttock pain & -45.6 & 9.4 & 15 & -8 & 5.2 & 50 & 0.0009 \\
\hline Bloated feeling & -25.4 & 10.0 & 15 & -5.05 & 3.5 & 48 & 0.0178 \\
\hline Dry mouth & -21.5 & 9.3 & 13 & -6 & 4 & 50 & 0.0944 \\
\hline Hair loss & 8.3 & 9.3 & 13 & 10.7 & 3.1 & 47 & 0.7538 \\
\hline Trouble with taste & -15.4 & 12.5 & 13 & 6.6 & 2.3 & 50 & 0.0059 \\
\hline Flatulence & -21.1 & 9.9 & 15 & 0.17 & 4.3 & 41 & 0.2560 \\
\hline Fecal incontinence & -6.7 & 3.7 & 14 & -0.52 & 4.2 & 38 & 0.4016 \\
\hline Sore skin & -11.1 & 5.1 & 15 & -1.76 & 4.8 & 45 & 0.2901 \\
\hline
\end{tabular}

Table 6: Comparison between EBT and CRT mean score difference between pretreatment and 3 - 6 weeks post-treatment score using EORTC CR29.

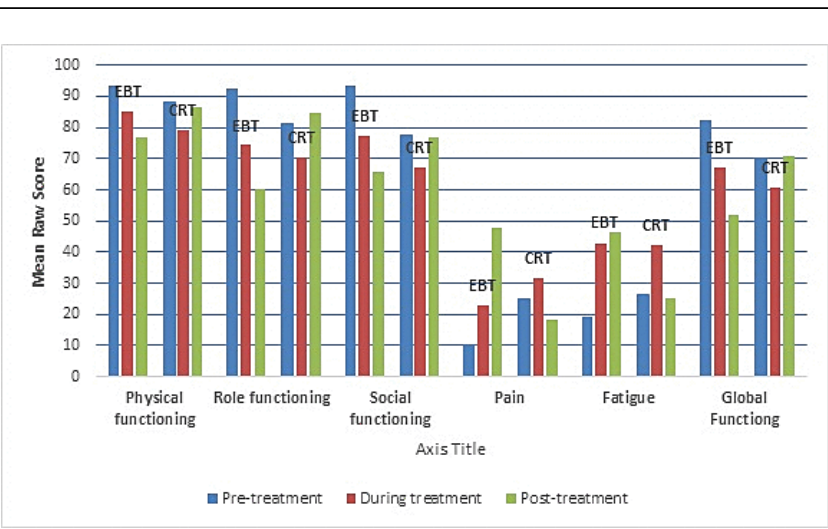

Figure 1: Raw mean scores for the comparison groups at all-time points for the scores on the EORTC C30; EBT: Endoluminal Brachytherapy CRT: Chemoradiation.

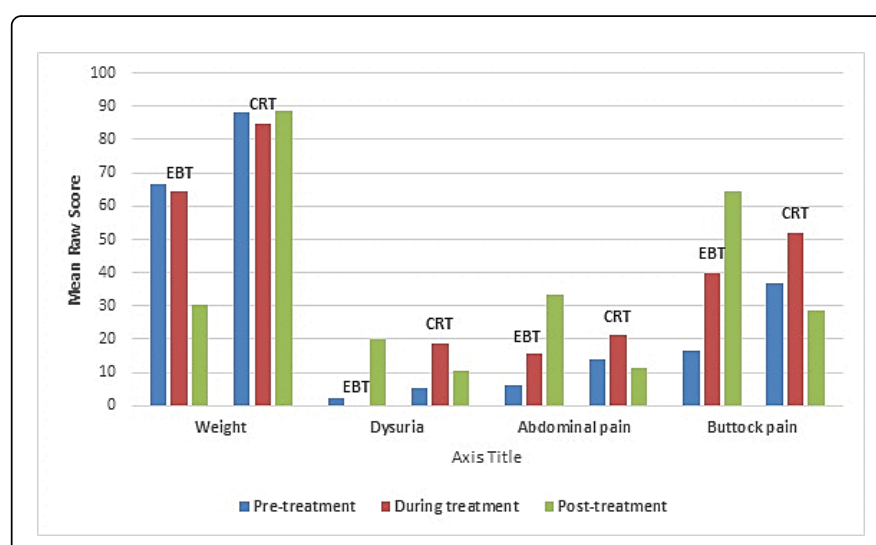

Figure 2: Raw mean scores for the comparison groups at all-time points for the scores on the EORTC QLQ-CR29; EBT: Endoluminal Brachytherapy CRT: Chemoradiation. 
Citation: Althumairi AA, Monn F, Herman JM, Narang AK, Hacker-Prietz A, et al. (2016) A Comparison of Post-treatment Quality of Life Outcomes for Endoluminal Brachytherapy and Chemoradiation for the Treatment of Localized Rectal Cancer. Arch Surg Oncol 2: 112. doi: 10.4172/2471-2671.1000112

Page 7 of 8

\section{Discussion}

In our prospective trial of high dose EBT for rectal cancer, we found a primary tumor pCR rate of $28.0 \%$ which is comparable to the EBT outcomes demonstrated by Young et al. [10]. Although, intraluminal radiation therapy appeared to be well tolerated by our patients, our data on symptoms and QOL suggested higher patient reported side effects with EBT. Grade 3 toxicity following EBT, although not statistically significant when compared to conventional CRT, was high (31.0\%). In EBT patients, the short-term functional QOL and symptoms scores worsened significantly when comparing pretreatment to post-treatment. When the difference in the mean pretreatment baseline scores and post-treatment scores from EBT was compared to similar time points during conventional CRT, several significantly worse reported symptoms and functional outcomes were found. Examining all time points evaluated for EBT and CRT (baseline, during treatment, and following treatment), patients undergoing CRT return to baseline scores at $3-6$ weeks while patients undergoing EBT do not. This may be a function of time since the end of treatment surveys are administered $9-12$ weeks later in the CRT patients and only 4 weeks later in the EBT patients.

Traditionally, the success of cancer treatment is measured by disease control and long-term survival. However, deeply imbedded in the development of multimodality treatment for rectal adenocarcinoma are the emphasis on QOL and the effect it has on treatment planning. In 2004, Sauer evaluated preoperative vs. postoperative radiation for rectal cancer and found that although there was no difference in overall survival, there was reduced acute toxicity in patients treated preoperatively [2]. Thus, this study solidified neoadjuvant therapy as the mainstay in the treatment of rectal cancer. Although this study focused on acute changes in QOL, most of the published literature has focused on long term QOL following radiation therapy. For example, Schmidt et al. [8] evaluated the effect of sphincter saving surgery in the management of rectal cancer patients and found that loss of the anal sphincter function was associated with poorer QOL and sexual function. Peeters et al. [16] in the Dutch TME trial demonstrated that irradiated patients had increased rates of fecal incontinence, mucus discharge, and pad usage as compared to non-irradiated patients. Recently, Guckenberger et al. [17] compared long-term QOL following short course external beam radiotherapy with long-course radiotherapy for locally advanced rectal cancer. Although this study was not randomized, he found the two treatment modalities to be comparable with regards to long-term QOL and reintroduced short course radiation into the algorithm for the management of rectal cancer.

Acknowledging the importance of QOL outcomes following the multimodality management of rectal cancer, we evaluated symptoms scores, functional scores, and toxicity at several time points. The oncological outcomes have already been well established from the McGill group and confirmed in our pilot study [10]. However, little is known about the short-term and long-term effects of EBT on QOL. Our pilot study was designed to look at both outcomes, however this manuscript only reports on the acute, short-term (prior to surgery) QOL outcomes from EBT. We chose a comprehensive assessment of all findings since clinical relevance in this study group is not entirely known. There are several important findings that should be discussed.

First, there were differences noted in the pre-treatment QOL between patients scheduled to undergo either EBT or CRT. Although very few of these difference reached statistical significance, there were many symptoms that varied more than 10 percentage points. This finding may be due to differences in demographics and clinical staging between the groups. However, since the control group is from an earlier time period, complete local staging data is not available. There is also a greater lapse in time when follow up questionnaires were completed by the control group vs. the study group due to the differences in treatment modalities. The possible effect of this can be seen in the Figures 1 and 2. In the control group, there is an increase in symptoms and decrease in QOL in many of the parameters studied during treatment, but following treatment at one month, many of the reported symptoms have returned to pre-treatment levels. However, in the EBT group, the symptom scores do not return to their pretreatment level. Upon evaluation of the EBT group at 3-6 weeks, Figures 1 and 2 demonstrates that many of the QOL variables are worse than baseline. Perhaps given another 6 weeks, the symptoms and QOL scores for the EBT group would return to pre-treatment levels. Another important finding is that our rate of APR in this small group of patients was $12.0 \%(2 / 17)$. Patients undergo anal sphincter excision with a permanent stoma are known to have worse functional outcomes overall. Although these assessments took place prior to surgery, this may have affected our findings since these patients may have been anticipating a permanent colostomy. We also found that patients indicated more dysuria following EBT than conventional CRT. Perhaps there is a local effect of EBT to the bladder and further studies need to be performed. Finally, we did have a larger proportion of female patients who underwent EBT. It is interesting to note that in the study by Schmidt et al. [8], they noted that female patients reported higher level of symptoms and treatment strain when compared to their male counterpart. Engel et al. [18] compared QOL in female breast cancer patients to males with rectal cancer. In this study, female breast cancer patient suffered more with physical functioning and fatigue as compared to their male counterparts.

There are several limitations to this study. First, the sample size of our study is small; however, this represents the entire pilot study population. The role of the pilot study was to examine safety and efficacy for EBT. The second phase of this study is multi-institutional and will allow for better recruitment. The small sample size limits our ability to look effectively using linear regression models at the plausible reasons for poorer outcomes (age, gender, surgery type, etc.). Finally, as with all QOL data, the patients received multiple questionnaires. There is a risk of over testing which may lead to mispresentation of the truth. Further studies looking with a large number of patients are necessary. Furthermore, long-term data may demonstrate stronger beneficial effect of EBT monotherapy.

\section{Conclusion}

Although EBT is an effective alternative, rectal cancer patients may experience worse global QOL and significantly more gastrointestinal symptoms following treatment. Efforts should be made to minimize these symptoms during treatment. Further studies are needed to determine the long-term effects of EBT on QOL.

\section{References}

1. Meyer J, Balch G, Willett C, Czito B (2011) Update on treatment advances in combined-modality therapy for anal and rectal carcinomas. Curr Oncol Rep 13: 177-185.

2. Sauer R, Becker H, Hohenberger W, Rödel C, Wittekind C, et al. (2004) Preoperative versus postoperative chemoradiotherapy for rectal cancer. $\mathrm{N}$ Engl J Med 351: 1731-1740. 
Citation: Althumairi AA, Monn F, Herman JM, Narang AK, Hacker-Prietz A, et al. (2016) A Comparison of Post-treatment Quality of Life Outcomes for Endoluminal Brachytherapy and Chemoradiation for the Treatment of Localized Rectal Cancer. Arch Surg Oncol 2: 112. doi: 10.4172/2471-2671.1000112

Page 8 of 8

3. Gérard JP, Conroy T, Bonnetain F, Bouché O, Chapet O, et al. (2006) Preoperative radiotherapy with or without concurrent fluorouracil and leucovorin in T3-4 rectal cancers: results of FFCD 9203. J Clin Oncol 24: 4620-4625.

4. André T, Boni C, Navarro M, Tabernero J, Hickish T, et al. (2009) Improved overall survival with oxaliplatin, fluorouracil, and leucovorin as adjuvant treatment in stage II or III colon cancer in the MOSAIC trial. J Clin Oncol 27: 3109-3116.

5. Bosset JF, Calais G, Mineur L, Maingon P, Stojanovic-Rundic S, et al. (2014) Fluorouracil-based adjuvant chemotherapy after preoperative chemoradiotherapy in rectal cancer: long-term results of the EORTC 22921 randomised study. Lancet Oncol 15: 184-190.

6. Herman JM, Narang AK, Griffith KA, Zalupski MM, Reese JB, et al. (2013) The quality-of-life effects of neoadjuvant chemoradiation in locally advanced rectal cancer. Int J Radiat Oncol Biol Phys 85: e15-19.

7. Wiltink LM, Marijnen CA, Meershoek-Klein Kranenbarg E, van de Velde C, Nout RA (2015) A comprehensive longitudinal overview of healthrelated quality of life and symptoms after treatment for rectal cancer in the TME trial. Acta Oncol 25: 1-7.

8. Schmidt CE, Bestmann B, Küchler T, Longo WE, Kremer B (2005) Tenyear historic cohort of quality of life and sexuality in patients with rectal cancer. Dis Colon Rectum 48: 483-492.

9. Ozgen Z, Ozden S, Atasoy BM, Ozyurt H, Gencosmanoglu R, et al. (2015) Long-term effects of neoadjuvant chemoradiotherapy followed by sphincter-preserving resection on anal sphincter function in relation to quality of life among locally advanced rectal cancer patients: a crosssectional analysis. Radiat Oncol 10: 168.

10. Vuong T, Devic S, Podgorsak E (2007) High dose rate endorectal brachytherapy as a neoadjuvant treatment for patients with resectable rectal cancer. Clin Oncol (R Coll Radiol) 19: 701-705.
11. Smith JA, Wild AT, Singhi A, Raman SP, Qiu H, et al. (2012) Clinicopathologic Comparison of High-Dose-Rate Endorectal Brachytherapy versus Conventional Chemoradiotherapy in the Neoadjuvant Setting for Resectable Stages II and III Low Rectal Cancer. Int J SurgOncol 2012: 406568.

12. Aaronson NK, Ahmedzai S, Bergman B, Bullinger M, Cull A, et al. (1993) The European Organization for Research and Treatment of Cancer QLQC30: a quality-of-life instrument for use in international clinical trials in oncology. J Natl Cancer Inst 85: 365-376.

13. Whistance RN, Conroy T, Chie W, Costantini A, Sezer O, et al. (2009) Clinical and psychometric validation of the EORTC QLQ-CR29 questionnaire module to assess health-related quality of life in patients with colorectal cancer. Eur J Cancer 45: 3017-3026.

14. Scott NW, Fayers PM, Aaronson NK, Bottomley A, de Graeff A, et al. (2001) EORTC QLQ-C30 Scoring Manual. 3. Brussels, Belgium: European Organization for Research and Treatment of Cancer.

15. Osoba D, Rodrigues G, Myles J, Zee B, Pater J (1998) Interpreting the significance of changes in health-related quality-of-life scores. J Clin Oncol 16: 139-144.

16. Peeters KC, Marijnen CA, Nagtegaal ID, Kranenbarg EK, Putter H, et al. (2007) The TME trial after a median follow-up of 6 years: increased local control but no survival benefit in irradiated patients with resectable rectal carcinoma. Ann Surg 246: 693-701.

17. Guckenberger M, Saur G, Wehner D, Thalheimer A, Kim M, et al. (2013) Long-term quality-of-life after neoadjuvant short-course radiotherapy and long-course radiochemotherapy for locally advanced rectal cancer. Radiother Oncol 108: 326-330.

18. Engel J, Kerr J, Schlesinger-Raab A, Eckel R, Sauer H, et al. (2003) Quality of life in rectal cancer patients: a four-year prospective study. Ann Surg 238: 203-213. 